\title{
A servidão involuntária: trabalho, educação e enraizamento em Simone Weil (I) ${ }^{1}$
}

\section{The involuntary servitude: work, education and rooting in Simone Weil (I) ${ }^{2}$}

\section{Luciano Costa Santos ${ }^{3}$}

\section{Resumo}

Neste artigo apresentamos uma introdução ao pensamento social da filósofa judia francesa Simone Weil, tendo como eixo a articulação de trabalho e educação à luz da categoria de enraizamento. Peregrinando de corpo e alma junto a operários, mineiros e camponeses, Simone Weil oferece ao mundo contemporâneo uma das mais consistentes contribuições reflexivas em favor da superação da opressão social imposta aos trabalhadores da produção, cuja "carne de trabalho" é por ela assumida como locus hermenêutico de uma radical reposição da questão sobre o sentido do humano. Na contramão da histórica divisão social do trabalho que promove a degradação do labor manual, Simone mostra que uma civilização não atinge o estatuto humano se aqueles que contribuem com as suas mãos para edificá-la não levam, de direito e de fato, uma vida humana. Na perspectiva dessa transgressão civilizatória, tratava-se de assegurar aos trabalhadores da produção os "alimentos" para a satisfação de suas necessidades humanas básicas, mas também sua plena inserção na vida do espírito, seja pela apropriação da cultura "clássica" e universal que lhes é sonegada, seja pela afirmação da cultura - única e inestimável - enraizada em sua experiência vital. Em suma, a perspicácia subversiva do pensamento de Simone Weil está em mostrar que a opressão social não somente usurpa a dignidade de operários e camponeses, como empobrece a própria civilização, ao privá-la de uma espiritualidade que só pode nascer do corpo e da alma dos trabalhadores.

Palavras-chave: Trabalho; educação; enraizamento; espiritualidade.

1 O artigo se divide em duas partes. A segunda parte do artigo segue no próximo número da Revista.

2 O artigo se divide em duas partes. A segunda parte do artigo segue no próximo número da Revista.

3 Doutor em Filosofia. Prof. Adjunto do Programa de Pós Graduação em Educação e Contemporaneidade (PPGEDUC) da Universidade do Estado da Bahia (UNEB). Email para contato: lucostasantos1@gmail.com 


\section{A mística militante}

Poucos pensadores contemporâneos realizaram tão indissolúvel enlace entre vocação intelectual e militância social quanto a filósofa francesa Simone Weil (1909-1943).

Primeira mulher na França a obter o título de agregação em Filosofia na École Normale Supérieure - sendo classificada à frente da famosa xará de Beauvoir -, os termos "militante" e "social" de saída soam precários para designar a insólita consagração de si que levou essa filha de judeus a intercalar o exercício docente com um persistente trabalho voluntário, pedagógico/político, junto a operários, mineiros e camponeses, chegando a viver com e como estes em alguns momentos de sua curta e acidentada existência.

Apelidada por suas alunas de "a virgem vermelha", misto de religiosa e revolucionária, aonde quer que fosse transferida para exercer o magistério, nos arrabaldes de Paris ou em cidades da província, Simone acomodava-se em pensões modestas de bairros periféricos e não admitia reter para si mais que a parte do salário correspondente à renda de um operário em greve, doando o restante a sindicatos de trabalhadores. Em 1934, licencia-se do magistério para empregar-se como anônima operária na linha de montagem da fábrica de automóveis Renault, a fim de conhecer por dentro a condição do trabalhador industrial, para cuja compreensão dedicou parte substancial de seu talento filosófico. Considerando que praticamente nenhum dos intelectuais de esquerda que pontificavam sobre a classe trabalhadora conhecia, de fato, o seu infortúnio, Simone não admitia pensar a condição operária sem assumi-la na carne. Para uma amiga que a instava a não comprometer sua promissora carreira intelectual com as agruras da vida operária - "Afinal, por que faz isso com o que você tem a dizer?" -, ela responde: "Há coisas que eu não teria podido dizer se eu não tivesse feito isso." (Weil, apud Bosi, E., 1996, 64, grifo nosso), sinalizando uma ética do pensamento de funda raiz e de graves exigências. 
Lâmpada de alta voltagem acesa no interior das engrenagens industriais, Simone Weil põe a nu o oco da alma da fábrica, que o pensamento marxista clássico já havia resumido na categoria alienação:

No nível do operário, as relações estabelecidas entre os diversos cargos, as diferentes funções, são relações entre as coisas e não entre os homens. As peças circulam com suas fichas, a indicação do nome, da forma, da matéria prima; pode-se quase acreditar que elas é que são as pessoas, e os operários são as peças intercambiáveis. Elas têm um estado civil; e quando é preciso, como em algumas grandes fábricas, mostrar na entrada um cartão de identidade onde se está fotografado com um número no peito, como um condenado, o contraste é um símbolo pungente que dói. As coisas representam o papel dos homens, os homens representam o papel de coisas; eis a raiz do mal. (Weil, apud Bosi, E., 1996, 162)

Como costuma acontecer com os ritos, o rito de passagem na Renault marca Simone Weil para o resto de sua vida:

Estando na fábrica... a infelicidade dos outros entrou na minha carne e na minha alma. Nada me separava dela. $\mathrm{O}$ que eu lá suportei me marcou de uma maneira tão duradoura, que ainda hoje, quando um ser humano, quem quer que ele seja, não importa em que circunstâncias, me fala sem brutalidade, não posso deixar de ter a impressão que deve haver algum engano, e que o engano vai sem dúvida, infelizmente, se dissipar. Eu recebi de uma vez por todas a marca da escravidão. (Weil, apud Bosi, E., 1996, 46/47)

Julgando insuficiente levar apoio aos operários, Simone leva-se a si mesma, assume a paixão operária e altera-se ao ponto de fazer-se, ela própria, operária. 
A ressonância da kenosis cristã ${ }^{4}$ nesse gesto não é fortuita. Embora por toda a vida não tenha se filiado a nenhuma igreja cristã - em solidariedade aos que permaneceram fora de seu abrigo confessional e por entranhado senso de liberdade espiritual -, Simone Weil não tardaria em aproximar-se do Cristo e admitir a sua divindade, considerando haver Ele se esvaziado de sua divina primogenitura a ponto de humilhar-se e, obediente até o fim, suportar a mais ignominiosa das mortes (Filipenses, 2,6-8). Para Simone, somente Deus poderia impor tamanha negação ao império do poder que a todos submete. Adorado do ponto de vista de sua onipotência, Deus não passaria de um ídolo à medida dos desejos humanos, ao passo que em Cristo, o Filho de Deus que se faz fraco por misericórdia, revelar-se-ia a divina excelência do amor sobre o poder. (Weil, apud Bosi, E., 1996, 66) De tal modo a Paixão de Cristo "constrange" Simone a crer que, para ela, a fé seria inclusive "mais fácil" se não houvesse nos Evangelhos qualquer referência à Ressurreição, com as promessas e prodígios que lhe correspondem. (Weil, apud Bosi, E., 1996, 65)

Nalguma medida, portanto, essa espiritualidade pascal já opera na paixão operária da filósofa da École Normale Supérieure, levando-a ao limite do despojamento de si em solidariedade aos trabalhadores moídos pelas engrenagens da Renault.

No ano seguinte, em viagem a Portugal, onde convalescia a beira mar das feridas abertas na fábrica, Simone tem ocasião de deparar-se, pela primeira vez, com uma expressão religiosa que lhe parecia em profundo acordo com a sensibilidade do povo pobre, ao entrar numa aldeia de pescadores no justo momento em que transcorria uma cerimônia conduzida pela gente simples do lugar:

4 Conceito do vocabulário teológico cristão que se refere ao movimento de esvaziamento de si pelo qual, em Cristo, Deus se faz humano e humilha-se até à morte de cruz. 
Num estado físico miserável, entrei nessa pequena aldeia portuguesa que era, ai! tão miserável também, sozinha, à noite, sob a lua cheia, no dia mesmo da festa do padroeiro. As mulheres dos pescadores faziam a volta aos barcos em procissão, levando círios, e cantando cânticos certamente muito antigos, de uma tristeza dilacerante... Ali, tive de repente a certeza de que o cristianismo é por excelência a religião dos escravos, que os escravos não podemos não aderir a ela, e eu entre os outros. (Weil, apud Bosi, E., 1996, 47-48)

Na exata contramão de Nietzsche, Simone Weil exalta o fato de que o cristianismo é, "por excelência", a religião dos escravos. A pungência de seu relato não trai qualquer afetação jacobina que sugira a redução dessa "excelência" ao aspecto político, como se a religião cristã tão somente se colocasse com os oprimidos contra os opressores, de modo a promover um reequilíbrio dialético de forças, isto é, como se em última instância estivesse em jogo levar o escravo a tomar o poder que lhe fora usurpado. Se fosse este o caso, não se sairia da órbita do ressentimento que Nietzsche pusera no centro da tradição judeo-cristã. No entanto, o que parece saltar aos olhos de Simone na aldeia portuguesa é que, seguindo a via da kenosis aberta pelo Cristo, a religião dEle nascida nasce, por sua vez, em íntima solidariedade com os excluídos e exilados deste mundo, inaugurando uma nova ordem de convivência de fora e para além do poder. Ao invés de possibilitar a mera inversão de poderes, e mais do que favorecer o empoderamento dos pobres, a fé cristã instauraria uma radical subversão do poder e, por isso, aqueles a quem todo poder é negado estariam, em princípio, melhor dispostos a aderir ao seu mistério.

Em Simone Weil, é a partir do prisma espiritual que se tem como estimar o alcance do engajamento social; é na paixão solidária que se enraíza o projeto revolucionário; é pela mística que se decifra a militância - e não o inverso. A desconsideração dessa prioridade hermenêutica comprometeria em definitivo o seu pensamento, e a singular "virgem vermelha" não passaria de uma militante moldada pelo aparelho político e tingida de exótico verniz hagiográfico. 


\section{O malheur operário}

Na perspectiva até aqui considerada, a compreensão da condição escrava implica a remissão da categoria social de classe à categoria existencial de malheur, termo que ocupa lugar axial na obra weiliana e guarda poderosas evocações semânticas. ${ }^{5}$ Ora traduzido como "desgraça", "infelicidade" ou "infortúnio", no pensamento de Simone Weil malheur designa, ao mesmo tempo - e inextrincavelmente - miséria social, sofrimento físico, desamparo afetivo e abandono espiritual, indicando uma extrema decadência que se abate sobre o ser humano até ameaçar arrancar-lhe a própria humanidade. Se apenas um desses elementos (social, físico, psíquico ou espiritual) não estiver presente, já não se trata de malheur tal como Simone o concebe. O malheur fere a condição humana por inteiro. É porque a opressão de classe o expõe inerme ao constante aguilhão do malheur, que o pobre configura o humano em estado primário - nu e cru - e tem certa precedência simbólica nos processos de humanização. Nesse sentido, solidarizar-se com o pobre, vítima do malheur, é mover o gesto mais direto e reto em favor do humano. E é por abraçar, como nenhuma outra, o malheur inscrito na miséria humana que, para Simone, o cristianismo é, por excelência, a religião dos escravos: em sua senda, aprende-se a ir espiritualmente tanto mais fundo quanto humanamente mais baixo.

Concebida no horizonte do malheur, a ação política ganha inaudita profundidade: deixa de restringir-se à reivindicação de direitos no espaço público e passa a ter como centro irradiador a luta em favor da satisfação de necessidades humanas, das quais o malheur - indigência radical - justamente constitui a mais acabada e dramática expressão.

\footnotetext{
5 Cf. MARTINS, Alexandre Andrade. A Pobreza e a Graça - Experiência de Deus em Meio ao Sofrimento em Simone Weil. São Paulo: Ed. Paulus, 2013.
}

102 - Universidade Católica de Pernambuco 
Dentre as necessidades humanas, a fome é, em certo sentido, a primeira: "A consciência humana jamais variou sobre esse ponto. Todo o mundo imagina o progresso como sendo inicialmente a passagem a um estado da sociedade humana em que as pessoas não passarão fome." (Weil, $2001 \mathrm{a}, 10$ ) Sendo primeira, a obrigação de matar a fome é também, e por assim dizer, prototípica, já que em toda necessidade humana, física ou anímica, atua uma falta análoga de "alimento" que precisamente urge suprir: "Em consequência, a lista das obrigações para com o ser humano deve corresponder à lista daquelas necessidades humanas que são vitais, análogas à fome." (Weil, 2001 a, 10) Em suma, fazer política é mobilizar-se no âmbito do espaço público para assegurar ao ser humano o acesso aos "alimentos" substanciais de que ele precisa para realizar-se como tal.

Não estando condicionadas a jurisprudências, costumes ou convenções - como o não estão as necessidades que lhes correspondem -, tais obrigações inscritas na ação política concernem a uma vocação imutável e irrenunciável do ser humano: "Esta obrigação é eterna. Ela corresponde ao destino eterno do ser humano. Só é eterno o dever para com o ser humano como tal." (Weil, 2001 a, 9) Em contrapartida, os direitos estão sujeitos à imposição de circunstâncias, em certo sentido dependem do reconhecimento alheio para terem valia e só ganham efetivo sentido quando dão lugar à respectiva obrigação devida ao seu portador. Assim, outra marca do pensamento weiliano é a subordinação do peso - ético e político - do direito ao da obrigação: "Um homem, considerado em si mesmo, tem somente deveres, entre os quais se encontram certos deveres para consigo próprio. Os outros, considerados de seu ponto de vista, têm somente direitos. Um homem que estivesse sozinho no universo não teria nenhum direito, mas teria obrigações." (Weil, 2001 a, 7) Ao passo que a obrigação tem como correlato a dimensão do humano que lhe cabe salvaguardar - e por isso é irrecusável -, na reivindicação do direito pode insinuar-se a defesa do interesse estritamente individual de quem o invoca. Enquanto numa o bem é o moto principal, no outro a força do interesse (ou o interesse da força) pode imiscuir-se à 
justiça ao ponto de sequestrá-la. Nessa precedência de sentido da obrigação sobre o direito, radicaria a distinção entre a política maior - enraizada no eterno - e a política menor, subordinada a critérios de legitimidade impostos por pressões corporativas e contingências históricas, e que periga não ir além da disputa territorial pelo poder.

O malheur - síndrome de miséria, sofrimento e abandono, ou fome radical - produzido pela opressão social constitui, no pensamento weiliano, a suma do que precisa ser politicamente enfrentado e o reverso do que exige ser construído. Em última instância, a ideia mesma de transformação social é concebida como resposta ao malheur: "A lista concreta das dores dos operários fornece a lista das coisas a modificar." (Weil, $2001 \mathrm{a}, 53$ ) Aqui, o sentido de utopia tem por horizonte não a simples repartição igualitária do poder ou sua supressão, mas a configuração de um cenário social que inviabilize a produção do sofrimento humano pela injustiça. Sem tomar o sofrimento a sério e a fundo - como mal da carne -, não é possível alcançar a gravidade da ação política tal como Simone Weil a concebeu e viveu. É na noite escura do malheur que se há de encontrar as luzes para o novo dia da história. E é por ter atravessado até o fim essa noite escura em toda sua espessura, assumindo as feridas antes que as causas - ou as causas derivadas das feridas - de operários, mineiros, camponeses, republicanos espanhóis e resistentes franceses, que essa peregrina do malheur não se deixou domar pela lógica esquemática das máquinas políticas e fundou um modo singular de participação pública, à esquerda da esquerda, insubmissa entre insubmissos, não revolucionária apesar de mística, mas tanto mais revolucionária quanto mais mística.

Em 1942, durante a ocupação alemã na França, Simone Weil exila-se em Londres, encarregada pela Resistência de examinar projetos para reorganizar o seu país após o fim da Guerra. A partir desse intenso trabalho de prospecção histórica, sob a chama dos acontecimentos, Simone redige um alentado relatório no qual elabora a sua própria compreensão dos processos civilizatórios que levaram ao catastrófico desenlace da Guerra, propondo am- 
plas vias prospectivas para um novo começo - da França e do Ocidente - após a Guerra. Trata-se de um exercício de filosofia da história que busca chegar às bases da civilização ocidental moderna, com os paradigmas epistemológico e antropológico que lhe correspondem, indicando seus limites e os impasses em que veio a dar. Escrito em ritmo febril, sob os achaques da tuberculose que a levaria à morte um ano depois - por vezes acontecia-lhe desmaiar sobre as páginas enquanto as redigia -, esse relatório viria à luz em 1949 com o título "O Enraizamento", e dele afirma Camus que "Parece impossível imaginar para a Europa um renascimento que não leve em conta as exigências que Simone Weil definiu." (Weil, apud Bosi, E., 1996, 69)

Simone Weil inscreve o enraizamento entre as necessidades da alma, caracterizando-o como "talvez a mais importante e a mais desconhecida" de todas elas. Mesmo admitindo ser uma das necessidades "mais difíceis de definir", assim o define: "Um ser humano tem raiz por sua participação real, ativa e natural na existência de uma coletividade que conserva vivos certos tesouros do passado e certos pressentimentos do futuro." E esclarece: "Participação natural, ou seja, ocasionada automaticamente pelo lugar, nascimento, profissão, meio. Cada ser humano precisa ter múltiplas raízes. Precisa receber a quase totalidade de sua vida moral, intelectual, espiritual, por intermédio dos meios dos quais faz parte naturalmente." (Weil, 2001 a, 43)

O que de saída chama a atenção na descrição acima é o seu flagrante contraste com o paradigma antropológico moderno: enquanto neste o ser humano é concebido como sujeito - ego cogito - que constitui o sentido da existência a partir da própria iniciativa de pensar, querer e agir, aqui ele "recebe" a quase totalidade de sua vida da participação numa coletividade a que está ligado antes e para além de sua decisão, e que lhe provê a preciosa herança de sentido (os "tesouros do passado") a partir da qual poderá abrir caminho para a construção do futuro. Sem o dom comunicado pelas raízes a que pertence, o ser humano não estaria disponível sequer para fazer a experiência de si mesmo como sujeito. 
Ora, para Simone Weil a perda dessas raízes existenciais constitui um dos problemas fulcrais da civilização contemporânea, e afeta especialmente os trabalhadores submetidos à opressão social, agravando o seu malheur: "Quase todas as reivindicações dos operários exprimem o sofrimento pelo desenraizamento." (Weil, 2001 a, 52) No contexto da sociedade industrial, somente o desempregado sofre um desenraizamento ainda maior ("de segunda potência") em relação ao do operário, o qual não se encontra em casa "nas fábricas, nos alojamentos, nem nos partidos e sindicatos supostamente feitos para eles, nem nos locais de prazer, nem na cultura intelectual se tentarem assimilá-la." (Weil, 2001 a, 45)

Ademais das conquistas coloniais que ameaçam subjugar uma sociedade do exterior, apropriando-se de sua mão de obra, e tanto mais opressivas se o colonizador permanece estrangeiro ao território conquistado, segundo Simone dois "venenos" internos às relações sociais de um país podem agravar (no contexto de sua época) a "doença" do desenraizamento operário. O primeiro deles é o dinheiro. Onde quer que entre, por si só o dinheiro tende a afrouxar os laços humanos e substituir todos os móbiles - reverência religiosa, consciência moral, afeição familiar, amor à pátria ou lealdade profissional, por exemplo - pelo simples desejo de ganho. Afinal, "nada é tão claro quanto uma cifra". (Weil, 2001 a, 44) Corroendo o senso de vínculo ou pertença, o desejo de ganho atinge o próprio sentido de raiz, favorecendo uma existência suspensa, sem base nutriz ou centro gravitacional, em deslocamento linear e indefinido, de ganho em ganho. Tal desapropriação existencial proporcionada pelo dinheiro atinge o paroxismo no caso do operário, que se vê reduzido a força produtiva - ou "carne de trabalho" - e obrigado a mensurar cada fração horária em função do valor da peça produzida, não dispondo de tempo, energia ou pensamento para outra coisa que não seja a aquisição do salário que assegure a reprodução de sua força de trabalho. 


\section{Educação e desenraizamento}

Para Simone Weil, o outro "veneno" que agrava o desenraizamento operário é o modelo de instrução vigente em seu tempo. Tal modelo remonta a um corte produzido no Renascimento, nos albores da modernidade, entre a cultura aristocrática, "culta", clássica, cujos modelos são herdados da Antiguidade greco-romana, e a cultura de massas, identificada com as tradições populares. Ora, o que se passou doravante é que essa cultura de elite, que se torna hegemônica na modernidade com a expansão burguesa, acaba por relegar a matriz grego-romana prezada pela antiga aristocracia palaciana, ao tempo em que consolida o distanciamento das tradições nacionais, dando lugar a um duplo desenraizamento - do patrimônio clássico e das tradições populares -, perdendo o horizonte universal e o chão local, instalando-se num limbo cultural cada vez mais restrito, "separado do mundo, numa atmosfera confinada, uma cultura consideravelmente orientada para a técnica e influenciada por ela, muito tingida de pragmatismo, extremamente fragmentada pela especialização, completamente desprovida ao mesmo tempo de contato com este universo e de abertura para o outro mundo." (Weil, 2001 a, 45)

$\mathrm{O}$ que se vê assim atingida nesse modelo moderno de instrução é a própria possibilidade de formação do sujeito, uma vez que se estreita ao mínimo a sua relação com a linguagem, ao lhe ser obstruído o acesso a duas das mais importantes fontes de sentido: o mundo da vida (lebenswelt) ${ }^{6}$, pré-reflexivo, cujo insondável manancial de percepções, afetos, crenças, símbolos, valores etc., recolhe-se e comunica-se nas tradições populares que atravessam os séculos; e a cultura clássica, decantada por critérios rigorosos de excelência, com seu elevado legado conceitual e artístico que resiste à corrosão do tempo. O cidadão mediano instruído

6 Termo cunhado por Husserl para designar a camada originária e pré-reflexiva de sentido, constituída a partir da relação sensorial e perceptiva da consciência com o mundo.

Ano 13 • n. 2 • jul./dez. 2013 - 107 
pela cultura formal se torna, assim, mais letrado e menos culto, mais prático e menos familiar ao próprio mundo:

Em nossos dias, um homem pode pertencer aos meios ditos cultos, por um lado sem ter nenhuma concepção a respeito do destino humano, por outro lado sem saber, por exemplo, que todas as constelações não são visíveis em todas as estações. Acredita-se comumente que um pequeno camponês de hoje, aluno da escola primária, sabe mais do que Pitágoras, porque repete docilmente que a terra gira em torno do sol. Mas de fato ele não olha mais as estrelas. Esse sol de que lhe falam na aula não tem para ele nenhuma relação com aquele que vê. (Weil, 2001 a, 45)

Numa instrução tão dissociada do mundo da vida, o empobrecimento dos conteúdos vai de par com o embrutecimento dos métodos de transmissão:

O que se chama hoje instruir as massas é pegar essa cultura moderna, elaborada num meio tão fechado, tão doentio, tão indiferente à verdade, tirar-lhe tudo o que ele ainda possa conter de ouro puro, operação que se chama vulgarização, e enfornar o resíduo tal e qual na memória dos infelizes que desejam aprender, como se enfia a comida pela goela dos pássaros. (Weil, 2001 a, 46)

Esvaziado de sentido, o saber passa a valer como pura moeda de troca e é acumulado exclusivamente em vista do sucesso profissional, convertendo-se o sistema de ensino em banco de dados a serviço da inserção no mercado. Na escola, os exames exercem sobre a juventude "a mesma obsessão que o dinheiro sobre os operários que trabalham por peça.” (Weil, 2001 a, 46) Em última instância, portanto, os dois fatores de desenraizamento diagnosticados por Simone Weil na sociedade contemporânea - o dinheiro e a instrução bancária - destilam, no fundo, o mesmo "veneno": o desejo de ganho.

Voltando-se para a juventude operária, Simone Weil dá-se conta de que a sua educação está por ser inventada, considerando a insuficiência das alternativas disponíveis para enfrentar 108 - Universidade Católica de Pernambuco 
os desafios em jogo. Com efeito, se é preciso imergir a formação do operário na produção - como nas escolas profissionais -, pois nesta se enraízam as experiências primárias de sentido que tecem o seu mundo da vida, não convém, entretanto, entregar a condução do processo educativo à fábrica, que o poderia submeter a critérios antes mercadológicos que pedagógicos. Por outro lado, se é preciso prover o operário de uma ampla cultura intelectual que o faça "sentir-se em casa no mundo do pensamento" (Weil, 2001 a, 63), tampouco semelhante tarefa poderia ficar restrita à escola convencional, cuja cultura barata e abstrata permanece limitada à facha social dos intelectuais burgueses e "funcionários públicos" que a produziram, sendo assim de difícil comunicação ao povo operário não por seu alto nível intelectual, mas por seu baixo teor humano. (Weil, 2001 a, 63) Um dos principais desafios da educação operária consiste, pois, em apropriar-se do estofo de experiências propiciado pelo mundo do trabalho, e nele implantar o que for acessível da cultura clássica universal, contribuindo para o surgimento de uma cultura popular, mas não vulgar, e intelectual, mas não abstrata.

Como, porém, tornar a cultura clássica acessível aos operários? É possível vencer o fosso histórico que os separam?

Para Simone Weil, o primeiro obstáculo que dificulta a aquisição de alta cultura pelo povo trabalhador é a falta de tempo e de forças. Esses obstáculos de ordem material atrapalham somente o aprendizado dos elementos inferiores ou médios da cultura, mas não vedam propriamente o acesso aos significados que nela se recolhem, pois "A verdade ilumina a alma na proporção de sua pureza e não de alguma espécie de quantidade. Um pouco de verdade pura vale tanto quanto muita verdade pura." (Weil, 2001 a, 64) Entende-se melhor essa afirmação à luz do conceito de atenção (attention), de importância central no pensamento weiliano, que se refere à atitude de aplicar o espírito por inteiro (ou de modo "puro") à recepção do que nele se apresenta. Devotar atenção a uma coisa, para Simone, é o gesto primário de generosidade que se lhe pode oferecer; é recebê-la como se ela estivesse a sair novamente das mãos de Deus. Nesse sentido, "A 
verdade mais vulgar, quando invade toda a alma, é como uma revelação." (Weil, 1986, 195). E: "A atenção absolutamente sem mescla, é oração.” (Weil, 1986, 196). Sendo assim, a maior valia na via do aprendizado não está em "compreender coisas novas", mas, "à força de paciência, de esforço e de método, chegar a compreender as verdades evidentes com todo o meu ser." (Weil, 1986, 195)

É por haver atestado tais "paciência", "esforço" e "método" - enfim, tal pureza de "atenção" - em tantos trabalhadores aos quais dedicou incansável assistência docente ao longo da vida, nas poucas horas de descanso que lhe restavam - a exemplo das aulas particulares de geometria a um aplicado operário tuberculoso sem esperança de cura -, que Simone assevera: "Se um operário, num ano de esforços ávidos e perseverantes, aprende alguns teoremas de geometria, ter-lhe-á entrado na alma tanta verdade quanto a um estudante que, durante o mesmo tempo, tiver posto o mesmo fervor para assimilar uma parte da matemática superior." (Weil, 2001 a, 64)

O segundo desafio para a formação dos operários é como transmitir-lhes a cultura intelectual, concebida a partir de uma sensibilidade e linguagem bastante distintas das suas. Como vimos, a solução jamais estaria na vulgarização da cultura, o que significaria torná-la acessível ao preço de tirar-lhe a vida:

Não tomar as verdades, já excessivamente pobres, contidas na cultura dos intelectuais, para as degradar, mutilar, esvaziar de seu sabor; mas simplesmente expressá-las, em sua plenitude, por meio de uma linguagem que, segundo a expressão de Pascal, as torne sensíveis ao coração, para pessoas cuja sensibilidade se acha modelada pela condição operária. (Weil, $2001 \mathrm{a}, 65$ )

A saída, portanto, não é banalizar, mas traduzir. Ora, o exercício de tradução é arte delicada e de suma importância, pois implica apropriar-se do sentido "em sua nudez" (Weil, 2001 a, 65), retendo-lhe o núcleo a fim de verter para outras linguagens o que nestas dele subsiste. O desafio da tradução engaja, assim, o tradutor no mais exigente trabalho de depuração linguística. Por 110 - Universidade Católica de Pernambuco 
outro lado, a tradução também constitui critério de credibilidade do dito, na medida em que uma das exigências primárias da comunicação é que o que faz sentido numa linguagem possa fazê-lo em qualquer outra. Mais ainda, o desafio de tradução lança a linguagem num processo de permanente reinvenção dialógica, ao incorporar outros vieses e acepções que contribuam para renovar e ampliar o seu próprio patrimônio semântico.

No caso aqui considerado, segundo Simone o esforço de transposição dos códigos da cultura intelectual para a sensibilidade do povo operário seria ainda "bem mais salutar" para aquela do que para este, ao obrigá-la a sair "da atmosfera irrespiravelmente confinada em que está encerrada", cessando de ser "uma coisa de especialistas de alto a baixo", tanto mais degradada quanto mais se vai para baixo. (Weil, 2001 a, 65) Com efeito,

Do mesmo modo que se tratam os operários como se se tratasse de secundaristas um pouco idiotas, tratam-se os secundaristas como se fossem estudantes universitários consideravelmente cansados, e os estudantes universitários como professores que tivessem sofrido amnésia e precisassem ser reeducados. A cultura é um instrumento manejado por professores para fabricar professores que por sua vez fabricarão professores (Weil, $2001 \mathrm{a}, 65$ )

Nessa cadeia descendente de transmissão da cultura moderna, o saber, que já nasce vulgarizado e estanque no estrato mais alto da pirâmide, torna-se ainda mais estanque e vulgar à medida que vai para a base, até chegar ao estudante operário já quase destituído de sentido, como puro dado informativo. Principal sintoma disto é a perda da perspectiva de relação entre os saberes, como se cada dado aprendido constituísse um ídolo mental destinado à pura retenção mnemônica, a exemplo do que ocorre no ensino da geometria, cujas noções dizem respeito a relações necessárias que estruturam o cosmos e incidem sobre grande parte dos fenômenos do mundo, não obstante desabarem sobre a cabeça do educando como um conjunto arbitrário e fragmentário de fórmulas. 
Ao cobrar que a cultura moderna seja traduzida para o operário - ao cobrar que ela fale ao operário -, Simone Weil exige que essa cultura preste contas da pertinência e atualidade do que tem a transmitir, mas, em contrapartida, também a incumbe de receber do operário - esse sujeito ocultado -, com seus humildes fazeres e misteres corporais, com seu trabalho cruciante e seu malheur, no limite entre a vida e a morte, a inestimável contribuição de uma experiência humana que faria tal cultura encontrar dimensões de sentido a que jamais chegaria por si mesma. Despertando-se o sujeito operário, Simone espera que este dê à cultura moderna a oportunidade de, afinal, ter algo a dizer.

À guisa de exemplo, Simone Weil sugere um expediente pedagógico simples para introduzir a noção geométrica de necessidade numa escola profissional, articulando a ciência à prática da oficina. Propostas aos aprendizes algumas tarefas laborais, eles deveriam executar as que fossem possíveis e justificar a impossibilidade das que não o fossem. Semelhante experiência começaria por introduzir "toda geometria" no espírito do trabalhador. Com efeito, "A execução é uma prova empírica suficiente da possibilidade, mas para a impossibilidade não há prova empírica; é preciso uma demonstração. A impossibilidade é a forma concreta da necessidade." (Weil, 2001 a, 67) Com isso, Simone pretende mostrar que a ciência clássica procede de um método analógico, consistindo em "transportar para a natureza as relações que dominam o trabalho humano" e, sendo bem ensinada aos trabalhadores, pertencer-lhes-á "bem mais naturalmente do que aos secundaristas." (Weil, 2001 a, 67) Subvertendo um viés axiológico que, desde os gregos, relega o labor fabril ao desprezo, estabelecendo sua suposta antinomia com o trabalho intelectual, Simone mostra que complexas relações geométricas atuam nas atividades manuais e que, se o corpo do operário não é visto como lugar privilegiado para o aprendizado da ciência, isto não se deve a razões de ordem pedagógica, mas a uma usurpação de origem econômica. 


\section{Referências}

BOSI, Ecléa (Org.). A Condição Operária e Outros Estudos sobre a Opressão. São Paulo: Ed. Paz e Terra, 1996, 2ª Ed.

MARTINS, Alexandre Andrade. A Pobreza e a Graça - e Experiência de Deus em Meio ao Sofrimento em Simone Weil. São Paulo: Ed. Paulus, 2013.

WEIL, Simone. O Enraizamento. São Paulo: EDUSC, 2001 a.

. Opressão e Liberdade. São Paulo: EDUSC, 2001 b.

. A Gravidade e a Graça. São Paulo: ECE Editora, 1986, $2^{\mathrm{a}}$

Ed.

. La Source Grecque. Paris: Ed. Gallimard, 1953, $8^{\mathrm{a}}$ Ed. 
